\section{Dong Min $\mathrm{Kim}^{1}$, Seok Won $\mathrm{Kim}^{2}$}

Departments of ${ }^{1}$ Internal Medicine, ${ }^{2}$ Neurosurgery, Chosun University College of Medicine, Gwangju, Korea

Corresponding Author: Seok Won Kim

Department of Neurosurgery, Chosun University College of Medicine, 365 Pilmun-daero, Dong-gu, Gwangju 61453, Korea

Tel: +82-62-220-3126

Fax: +82-62-227-4575

E-mail: chosunns@chosun.ac.kr

Received: December 12, 2016

Revised: March 2, 2017

Accepted: March 3, 2017
Copyright () 2017 by The Korean Spinal Neurosurgery Society

This is an open access article distributed under the terms of the Creative Commons Attribution Non-Commercial License (http://creativecommons.org/licenses/by-n c/4.0/) which permits unrestricted non-commercial use, distribution, and reproduction in any medium, provided the original work is properly cited.

\title{
Gas-Containing Cervical Epidural Abscess Accompanying Bacterial Meningitis in an Adult
}

Gas-containing spinal epidural abscesses are uncommon. Moreover, acute spinal epidural abscesses rarely complicate bacterial meningitis in adults. Here, we report a rare case of a gas-containing cervical epidural abscess accompanying bacterial meningitis. In spite of aggressive fluid and continuous antibiotic therapy after the isolation of Streptococcus anginosus and Streptococcus constellatus in the cerebrospinal fluid cultures, the patient showed remaining motor dysfunction and bladder involvement. Our experience suggests that the effort to prevent neurologic deterioration by emergent surgical decompression and drainage of pus is mandatory to avoid additional spinal cord dysfunction in patients with spinal epidural abscesses accompanying bacterial meningitis.

Key Words: Cervical spine, Abscess, Meningitis

\section{INTRODUCTION}

The neurological complications of bacterial meningitis include cerebrovascular involvement such as hydrocephalus, seizures, hearing impairment, cranial nerve palsies, and hemi- or quadriparesis, and systemic complications such as septic shock, or disseminated intravascular coagulation $^{10,12)}$. However, acute spinal epidural abscesses rarely complicate bacterial meningitis in adults. Spinal epidural abscesses are an uncommon occurrence with high morbidity and mortality in case of a delay in diagnosis. Moreover, gas-containing spinal epidural abscesses are extremely rare ${ }^{2,4-6}$. As far as the authors' knowledge, this case is unusual due to the extensive gas-containing spinal abscess accompanying bacterial meningitis in an adult. Here, we report an uncommon case of marked motor dysfunction as an unusual complication of a gas-containing acute spinal abscess accompanying bacterial meningitis.

\section{CASE REPORT}

A previously healthy 56-year-old male patient was admitted to the Otorhinolaryngology Department with a 5-day history of febrile sense and neck swelling with swallowing difficulty. At admission, he was alert, and his vital signs were stable except for a high fever, which was $39.2^{\circ} \mathrm{C}$, along with a sore throat; he was admitted to the Otorhinolaryngology Department. However, there was no focal infection in fiberoptic laryngoscopy, and due to the focal neuro- logical sign of a stiff neck, he was transferred to the Neurosurgery Department. On neurological examination his motor power and sensation were intact. Hematological investigation revealed leukocytosis with a total white blood cell (WBC) count of 12.760/ $\mathrm{L}$, elevation of his erythrocyte sedimentation rate, to $62 \mathrm{~mm} / \mathrm{hr}$ (normal range, $0-20 \mathrm{~mm} / \mathrm{hr}$ ), and C-reactive protein, to $13.2 \mathrm{mg} / \mathrm{dL}$ (normal range, below $0.5 \mathrm{mg} / \mathrm{dL}$ ). To rule out pyogenic meningitis, a lumbar cerebrospinal fluid (CSF) analysis was performed. The color of the CSF was purulent yellowish (Fig. 1). Lumbar CSF analysis revealed 2,937 WBC cells/ $\mathrm{LL}$ (poly:mono, 87\%:13\%) with a glucose level of $31.8 \mathrm{mg} / \mathrm{dL}$, and protein level of $232.9 \mathrm{mg} / \mathrm{dL}$. A computed tomography (CT) scan of the cervical spine demonstrated sparsely scattered gas in the prevertebral space of C4-5 and intraspinal canal of the C4-5 interspace (Fig. 2A). Magnetic resonance imaging (MRI) with gadolinium enhancement revealed an epidural abscess with air bubbles in the anterior aspect of the central spinal canal of $\mathrm{C} 4$ and $\mathrm{C} 5$, compressing the spinal cord and causing a large amount of retropharyngeal abscesses in the prevertebral space of $\mathrm{C} 1$ through $\mathrm{C} 7$ (Fig. 2B). Due to its ventral location in the epidural space, the patient underwent open pus and irrigation following gram-stain culture. A yellowish purulent material was identified and retropharyngeal abscess was drained via anterior approach. CSF cultures showed the growth of gram-positive Streptococcus anginosus and Streptococcus constellatus. S. anginosus was also isolated from retropharyngeal abscess. According to an antibiotics susceptibility test, he was 


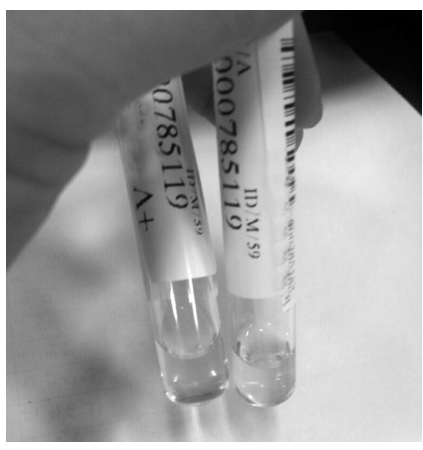

Fig. 1. Purulent yellowish cerebrospinal fluid collected in test tubes.
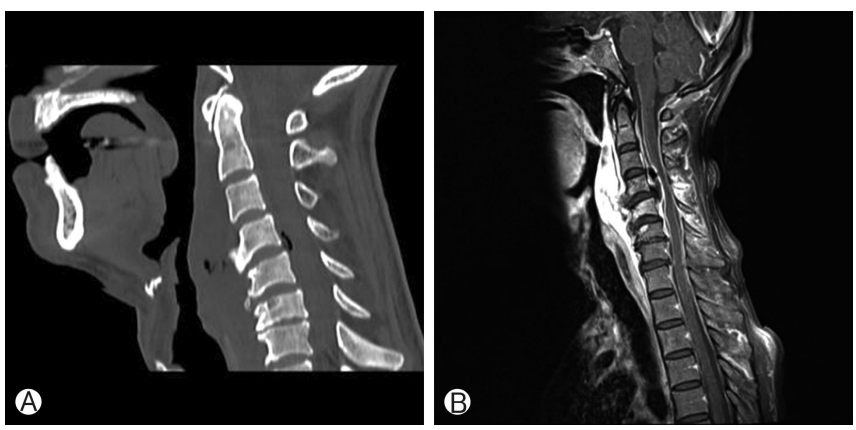

Fig. 2. Cervical computed tomography scan (A) and magnetic resonance image (B) show epidural abscess with air bubbles compressing anterior spinal cord at C4 and C5 and a large amount of retropharyngeal abscess.
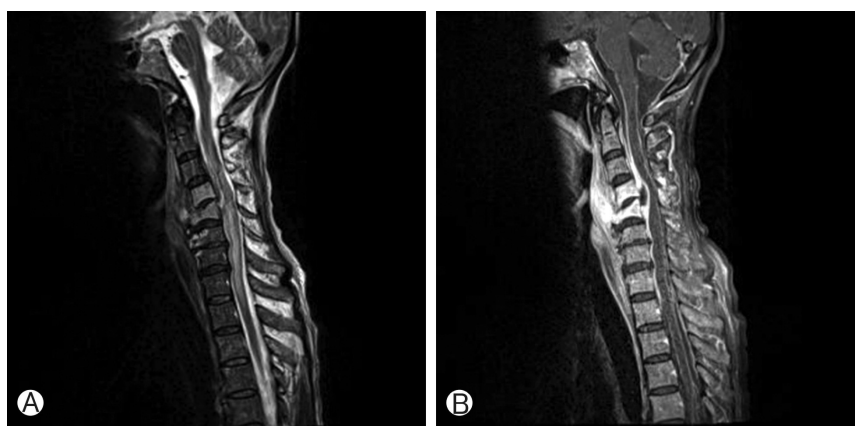

Fig. 3. T2-weighted sagittal image (A) and gadolinium enhanced magnetic resonance image (B) reveal extensive high signal intensity of the spinal cord at C5 through T1 and a remaining epidural abscess.

given Augmentin (GlaxoSmithKline. Middlesex, UK), Vancomycin (CJ pharmaceuticals, Seoul, Korea), and Metronidazole (CJ pharmaceuticals). Despite aggressive fluid and antibiotic therapy, he did not respond to treatment, in fact, his symptoms worsened. 10 days after admission, the patient's level of consciousness deteriorated gradually to a drowsy state and showed tetraparesis at GII/GIII. Brain MRI and magnetic resonance angiography with gadolinium enhancement showed no visible pathological enhanced lesions except for mild hydrocephalus. Cervical MRI with gadolinium enhancement revealed an aggravated high signal intensity of the spinal cord at the level of C5 through T1, suggesting spinal cord dysfunction with a remaining ventral epidu-
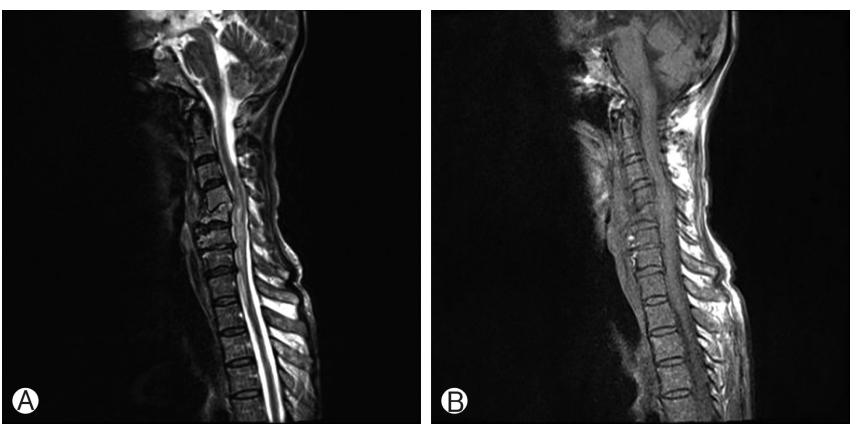

Fig. 4. T2-weighted sagittal (A) and gadolinium enhanced magnetic resonance (B) images at 60th day after admission show the absorbed retropharyngeal and epidural abscesses without enhancement.

ral abscess pocket (Fig. 3). At this time, the patient's body temperature was $39.8^{\circ} \mathrm{C}$. WBC count steadily rose to 18.295 cells $/ \mu \mathrm{L}$, heart rate to 120 beats/min, respiratory rate to 24 breaths/ min, and arterial $\mathrm{CO}_{2}$ tension to $26 \mathrm{mmHg}$, which indicated a septic condition. He was transferred to Infectious Diseases Department. On the 60th day of hospitalization, at the end of the prolonged antibiotic treatment, MRI revealed a marked regression of the lesions compared to the previous MRI, but little clinical improvement (Fig. 4). He was awake, alert, and oriented, but his muscle strength and occasional urinary incontinence were not improved. He was not able to walk by himself due to the flaccidity of both feet. Deep tendon reflexes were also persistent appeared in the lower extremities.

\section{DISCUSSION}

This case is unusual in some aspects. First, gas-containing spinal epidural abscesses are extremely rare. Second, acute spinal epidural abscesses rarely complicate bacterial meningitis in adults. Third, a causative pathogen of the meningitis was isolated, but the patient subsequently had residual abnormalities, such as motor dysfunction and bladder involvement, caused by spinal cord dysfunction. To the best of our knowledge, a gas-producing spinal epidural abscess complicating bacterial meningitis has never been reported in an adult. Spinal epidural abscess is a diagnosis that may constitute a neurological emergency, which can result in catastrophic and irreversible neurological damage in the case of a delay in diagnosis ${ }^{1)}$.

Usually, a fever and neck or back pains are the initial symptoms of a spinal epidural abscess. However, by the time of diagnosis, patients usually develop motor and sensory deficits with a loss of sphincter control. Patients with diabetes and those on systemic steroids are at higher risk, and the outcome in these groups is worse. The pathogenesis of spinal epidural abscesses involves several mechanisms. Infection may occur via direct extension of a local process (vertebral osteomyelitis, perinephric, retropharyngeal or psoas abscesses, or decubitus ulcers) or by hematogenous or lymphatic spread ${ }^{4}$. Ischemia of the spinal cord is the principal pathological process, along with thrombosis of leptomeningeal vessels and compression of spinal arteries. Other 
causes of ischemia are hypoperfusion resulting from shock or compression of the spinal cord, or edema or inflammation associated with arachnoiditis ${ }^{9}$.

Cerebral septic venous thrombosis is a well-recognized complication of purulent meningitis, and compromised venous drainage of the spine, septic venous thrombosis, or adhesive arachnoiditis is also conceivable in meningitis ${ }^{3}$. In this case, spinal cord dysfunction resulted from the cervical epidural abscess complicating bacterial meningitis. Plain radiographs are usually normal unless there is concomitant vertebral osteomyelitis. CT may show a loss of epidural fat, abnormal enhancement between bone and the dural sac, and an intraspinal space-occupying soft tissue mass $^{7}$. However, MRI reveals the extent and location of an abscess better than CT. MRI can also detect spinal and paraspinal infections, and is now recommended as a radiological exam in spinal infection ${ }^{8)}$. Early surgical drainage of pus is considered as the mainstay of the treatment for spinal epidural abscess ${ }^{11)}$. In spite of the appropriate therapy, residual abnormalities such as motor dysfunction or bowel and bladder involvement continue to exist in most patients, as has been reported in 18 survivors out of 23 patients with spinal cord dysfunction after bacterial meningitis in a study conducted by Moffett and Berkowitz ${ }^{9)}$ The present case is unusual due to the possibility of connection or dissemination between extensive retropharyngeal abscess and cervical spine and meninges. The causative organisms were isolated from the CSF culture and retropharyngeal abscess. Due to the anterior location of the pus, surgical decompression of the pus was not performed in compliance with the wishes of his family and patient's refusal of surgical treatment. In such situations, a prolonged course of adequate antibiotics is essential.

\section{CONCLUSION}

We report a rare case of a gas-producing epidural abscess complicating bacterial meningitis in an adult. The effort to prevent neurologic deterioration by emergent surgical decompression and drainage of pus is mandatory to minimize the morbidity and mortality resulting from misdiagnosis.

\section{CONFLICT OF INTEREST}

No potential conflict of interest relevant to this article was reported.

\section{ACKNOWLEDGEMENT}

This study was supported by research fund from Chosun University 2016

\section{REFERENCES}

1. Angtuaco EJ, McConnell JR, Chadduck WM, Flanigan S: MR imaging of spinal epidural sepsis. AJR Am J Roentgenol 149:12491253, 1987

2. Bang JH, Cho KT: Rapidly progressive gas-containing lumbar spinal epidural abscess. Korean J Spine 12:139-142, 2015

3. Kastenbauer S, Winkler F, Fesl G, Schiel X, Ostermann H, Yousry TA, et al: Acute severe spinal cord dysfunction in bacterial meningitis in adults: MRI findings suggest extensive myelitis. Arch Neurol 58:806-810, 2001

4. Kirzner H, Oh YK, Lee SH: Intraspinal air: a CT finding of epidural abscess. AJR Am J Roentgenol 151:1217-1218, 1988

5. Lee JK, Kim SH, Kim ES, Kim TS, Jung S, Kim JH, et al: Surgical treatment of the spontaneous spinal epidural abscess. J Korean Neurosurg Soc 29:1037-1042, 2000

6. Lee JS, Choi SM, Kim KW: Triparesis caused by gas-containing extensive epidural abscess secondary to Aeromonas hydrophila infection of a thoracic vertebroplasty: a case report. Spine J 13: e9-14, 2013

7. Leys D, Lesoin F, Viaud C, Pasquier F, Rousseaux M, Jomin M, et al: Decreased morbidity from acute bacterial spinal epidural abscesses using computed tomography and nonsurgical treatment in selected patients. Ann Neurol 17:350-355, 1985

8. Mackenzie AR, Laing RB, Smith CC, Kaar GF, Smith FW: Spinal epidural abscess: the importance of early diagnosis and treatment. J Neurol Neurosurg Psychiatry 65:209-212, 1998

9. Moffett KS, Berkowitz FE: Quadriplegia complicating Escherichia coli meningitis in a newborn infant: case report and review of 22 cases of spinal cord dysfunction in patients with acute bacterial meningitis. Clin Infect Dis 25:211-214, 1997

10. Pfister HW, Feiden W, Einhäupl KM: Spectrum of complications during bacterial meningitis in adults. Results of a prospective clinical study. Arch Neurol 50:575-581, 1993

11. Rigamonti D, Liem L, Sampath P, Knoller N, Namaguchi Y, Schreibman DL, et al: Spinal epidural abscess: contemporary trends in etiology, evaluation, and management. Surg Neurol 52:189-196, 1999

12. Tunkel AR, Scheld WM: Acute bacterial meningitis. Lancet 346: 1675-1680, 1995 